\section{WHAT EVERYONE SHOULD KNOW ABOUT CANCER}

I $\mathrm{N}$ THE whole medical world there is no more important subject requiring attention and prompt solution than the control of cancer. Eaucation as to the known facts concerning this disease is a duty the profession owes to humanity. A recent survey shows that there are more adult deaths from cancer today than from any other malady except heart disease. Irrespective of the question whether or not the cancer death rate is increasing, the fact remains that it is the second leading cause of death and that the actual number of deaths in the United States alone exceeds 140,000 .

Statistics prove that the average cancer patient, after discovering that something is wrong, usually waits months or even a year or more before obtaining medical advice or treatment. One reason for this is that patients do not realize that cancer starts from a trifling beginning. Certainly at least half and possibly three-fourths of the deaths from cancer are unnecessary, for this waste of life may be prevented in certain forms of the disease.

The three predominating causes of these unnecessary deaths are ignorance, fear, and delay in seeking advice. We need coordinated efforts of laymen and doctors to bring about a remedy. What the medical profession knows about this subject the laymen should know, and the most important fact is that cancer can be cured if discovered early, and treated in its beginning. Consequently, the early discovery of the disease is the only way at present which will enable the establishing of a cure.

Ignorance of what has been accomplished in this war against cancer is one of the reasons the public does not seek advice before it is too late. In the cancer clinics of this country and Europe more and more

This talk was made before the student assembly of the State Teachers College at Harrisonburg on Friday, November 20. people are being saved because they come early for help.

Cancer always begins in a small localized area, and if treated early is curable. The disease is insidious in its onset, and the early symptons are not alarming. Above all other causes of delay in seeking treatment is the absence of pain. As the early symptoms seem so unimportant, it is not strange that the average person fails to appreciate their possible significance. Cancer may begin at any age, although the vast majority of cases occur during middle and later life. Cancer is not contagious and it is not a blood disease. Therefore there is no danger of contracting it by contact.

The exact cause that makes a group of cells start to grow wildly beyond their normal limits and invade surrounding tissues is not known. Yet we do know that there are conditions predisposing to this state Therefore, by preventing or correcting these precancerous factors, cancer itself may be kept from developing.

Prolonged irritation of the lips, tongue, or inside of the mouth, from sharp or broken teeth, ill-fitting dental appliances, syphilis, and tobacco may produce a sore or ulcer that does not tend to heal. This may become the exciting cause of cancer. Good dentistry has definitely reduced the percentage of cases of cancer of the jaw.

Cancer frequently begins in moles or pigmented warts which are irritated, or are made to bleed and kept sore by repeated injury. These lesions are perfectly harmless at first, and become dangerous only after they have been irritated for a long time.

Neglected injuries resulting from childbearing may be a precancerous condition. Consequently, all such injuries should be repaired as a measure of protection against cancer.

It has long been known that irritating substances such as soot, tar, crude petroleum and certain chemicals may set up an irritation which may lead to cancer. 
Such precancerous conditions of the external and accessible parts of the body are readily cured, and the disease prevented. Precancerous conditions of the internal organs are, however, easily overlooked as the early symptoms are often obscure. It is important for any one who was any disturbance of the stomach or intestines which cannot be promptly and satisfactorily accounted for, to go promptly to a physician properly trained and equipped to make a thorough examination. Thus by proper modern chemical methods and by the use of the $\mathrm{X}$-ray a diagnosis can often by made early.

The importance of avoiding delay is demonstrated by the fact that probably $80 \%$ of cancer patients seek relief too late. Consequently any irregularity or imperfect functioning of an internal organ should be investigated promptly.

Fear, next to ignorance, is the greatest obstacle to combat in the war against cancer as it causes delay. Knowledge is the antidote to fear, and in the majority of cases if the patient seeks advice early, his fears may be dispelled, and he will be happy in knowing that there is no malignant disease, or that it is amenable to cure.

You are already educated to the value of going to your dentist periodically for an examination, and modern women have been taught the great importance of prenatal and postnatal care to guard against many serious complications of childbirth. The public has learned many truths which help in the prevention of tuberculosis. It is likewise important to have periodic examinations, at least once a year, as a safeguard against cancer, and such examinations may disclose other diseases in their incipiency when corrections may be made before it is too late.

When cancer exists the only cures available at present are surgery, radium, the Xrays, or a combination of these in the early stages of the disease.
Beware of so-called "cancer cures," as there is no specific cure for cancer, and there will be none until the actual cause of the disease has been discovered.

Noland M. Canter

\section{EDUCATIONAL BROADCASTING}

Educational broadcasting will be the subject of a national conference at the Hotel Mayflower, Washington, D. C., on December 10,11 , and 12, 1936, which will be sponsored by eighteen national organizations in co-operation with the United States Office of Education and the Federal Communications Commission and will serve as a clearing house for information on the latest technical and professional developments in the educational use of radio.

The program will include such topics as schools of the air, radio music, speech and drama, religious broadcasts, forums on the air, organization of listening groups, radio workshops, broadcasting to schools, use of radio programs by colleges and universities, use of radio by libraries and museums, radio programs for children, problems of research in educational broadcasting, audience attitudes, educational broadcasting in other countries, and organizing the community on behalf of a radio station.

All organizations interested in radio as a social force, nationally or regionally, are invited to participate. The broadcasting industry will be represented. Government officials and prominent educators from America and foreign countries will take part. The Executive Secretary of the Conference is C. S: Marsh, 744 Jackson Place, Washington, D. C.

More schools report using motion pictures for teaching of science than for instruction in any other school subject. Next comes travel and geography, and then history, social science, health, English, nature study, and commerce and industry. 